\title{
The Research on the Problems and Solutions in the Promotion of Social Responsibility of Corporations in Gansu Province under the Background of Low Carbon Economy
}

\author{
Xiaofang Zhang ${ }^{1}$ \\ ${ }^{1}$ College of Management, Northwest Minzu University, Lanzhou, China \\ Correspondance: Xiaofang Zhang, Associate Professor, College of Management, Northwest Minzu University, \\ Lanzhou, China.
}

Received: July 11, 2016

doi:10.5430/jms.v7n3p46
Accepted: July 23, 2016

Online Published: August 17, 2016

URL: http://dx.doi.org/10.5430/jms.v7n3p46

This research was supported by The Fundamental Research Funds for the Central Universities of Northwest Minzu University (Grant No. 31920150110).

\begin{abstract}
The performance of corporate social responsibility affects the development of low carbon economy to a certain extent under the background of low carbon economy. The research on the promotion of corporate social responsibility is very important to the development of low-carbon economy. Taking Gansu Province as an example, this paper studies the problems existing in the promotion of corporate social responsibility, and puts forward the corresponding countermeasures from the corporation itself, the government and other stakeholders.
\end{abstract}

Keywords: low carbon economy, corporate social responsibility, solutions

The concept of "low carbon economy" was first proposed in the United Kingdom's white paper which was named "the future of our energy - create low carbon economy" in 2003. It argues that the low carbon economy is to gain more economic output by less environmental pollution and less natural resources consumption, and puts forward the general goal of energy development in the United Kingdom as a low carbon economy country. Its essence is the comprehensive development model that takes low energy consumption, low emissions, low pollution economic development as the core, takes social development as the carrier, environmental pollution as the cost, and technological innovation as the key. In the development of low carbon economy, the lack of corporate social responsibility hinders the development of low-carbon economy to a certain extent, and it is very important to study the corporate social responsibility under the background of low carbon economy in the context. Taking Gansu Province as an example, this paper studies the problems and solutions in the promotion of corporate social responsibility under the background of low carbon economy.

\section{The Relationship between Low Carbon Economy and Corporate Social Responsibility}

Energy and environmental issue has become the key factor which restricts the healthy and rapid development of the economy. Under the guidance of the concept of sustainable development, promoting the development of low carbon economy is a fundamental and effective countermeasure. The development of low carbon economy can't be separated from the corporate social responsibility which is the main force of the development of low carbon economy. The situation of corporate social responsibility is closely related to the development of low carbon economy.

Firstly, the development of low carbon economy requires the corporation to change the mode of economic development from the pursuit of profit maximization to the pursuit of sustainable development of low-carbon, low pollution, low energy consumption. The development of low carbon economy requires corporation to achieve low carbon development as the goal of development. Corporations should not only take the economic responsibility, legal responsibility and moral charitable responsibility, but also more environmental responsibility.

Secondly, the performance of corporate social responsibility can better promote the development of low carbon economy. In the long term benefits, the performance of corporate social responsibility can not only enhance the corporate image, but also can strengthen the green technology innovation motivation and stimulate technological 
innovation behavior of the corporation. Efficiency improvement and cost savings caused by innovation can ultimately improve its market competitiveness. The improvement of the competitiveness of corporation will promote the better performance of social responsibility, so as to promote the development of low-carbon economy.

\section{Problems in the Promotion of Social Responsibility of Corporations in Gansu Province under the} Background of Low Carbon Economy

The development level of low carbon economy is closely related to the performance of corporate social responsibility. While developing low carbon economy vigorously, Gansu Province also promotes the performance of corporate social responsibility constantly. However, there are still some problems in the process of fulfilling corporate social responsibility.

\subsection{Problems Existing in the Corporation Itself}

The corporation is the main body of the social responsibility which relates to the corporation itself closely. It is very important to find the problems in the process of promoting social responsibility from the corporation itself.

\subsubsection{Corporate Social Sense of Responsibility Is Not High}

Whether a company is willing to undertake corporate social responsibility or not is related to the extent of corporate managers' awareness of social responsibility. Gansu Province is located in the remote area of northwest where foreign exchange is not as good as the coastal open city, and the people's minds are limited, so they cannot accept new things quickly, most of whom lack the awareness of low-carbon economy. The social responsibility awareness of the corporate managers in Gansu province is uneven and the understanding of corporate social responsibility of many corporate managers is still in the stage of perceptual knowledge. They do not have the concept of corporate social responsibility and still pursue the principle of profit. Above all, corporate social responsibility awareness is generally weak.

2.1.2 Many Corporations Are in the Stage of Capital Accumulation, and the Ability to Undertake Social Responsibilities Is Limited

The corporate capability and willingness to undertake the social responsibility is closely related to its scale, profitability and competitive ability. Only when the corporation reaches a certain size and has a certain profitability and competitive ability, is it possible to undertake more corporate social responsibility. Large scale corporations in Gansu Province are relatively few, while most are small and medium corporations. Compared with large corporations, small and medium-sized corporate life cycle is relatively short, so they need large amounts of capital accumulation to maintain their existence. They do not have the capacity to undertake more corporate social responsibilities and rarely take into account the interests of the society and the public, thus hindering the promotion of corporate social responsibility of the entire region and society.

\subsection{Problems Existing in the Government}

The government which can effectively promote the fulfillment of corporate social responsibility by virtue of its administrative power is the main promoter of corporate social responsibility. The government has the following problems in the process of promoting corporate social responsibility performance:

\subsubsection{Government Policy Is Not Perfect, Lack of Education and Guidance}

The root of the lack of social responsibility of corporations in China is the scarcity of institutional arrangements. The government is the policy maker, whose impact on corporate social responsibility is mainly concentrated in the institutional level, and the government relys on the system to restrict and guide the social performance of corporations. If the government policy is missing or not perfect, the direct result is to cause the corporations to have no chapter to follow. Only through the formulation of relevant laws and regulations to restrict the behavior of corporations, can it ensure the corporations to undertake the corresponding social responsibility. Although China has formulated a number of laws and regulations, it hasn't yet established a perfect legal system of corporate social responsibility which can regulate and restrict the performance of corporate social responsibility effectively. In recent years, Gansu Provincial Government has also made a lot of efforts in promoting the construction of corporate social responsibility. It plays a more and more important roles, but part of the government administrative behavior is not standardized in some extent and the enthusiasm of corporations to fulfill their social responsibility is restricted and reduced. At the same time, the government education guidance work is not in place, which leads to the lack of awareness of corporate social responsibility. 
2.2.2 The Evaluation and Supervision System Is Not Perfect, and the Implementation of Laws and Regulations Is Ineffective

Effective evaluation and supervision system can promote the corporations to fulfill the corporate social responsibility. However, it has not yet formed a systematic mechanism in our country, and there is no authoritative organization to evaluate and supervise the corporate social responsibility. Although $<$ Chinese industrial corporations social responsibility evaluation index system> (Trial) was issued by China Industrial Economic Association in 2013, it just standardized the evaluation index system of corporate social responsibility, and has not yet formed a set of effective evaluation criteria. Some important laws and regulations of our country are relatively backward and difficult to implement. In the specific implementation, may be due to the "power" is greater than "rule of law" which makes the laws vary from person to person. At the same time, local governments and corporations are the community of interests, so local protectionism has seriously impeded the justice of law enforcement and favor local interests. Gansu provincial government is not good enough to do in the evaluation and supervision of social responsibility.

\subsection{Problems Existing in Other Stakeholders}

Whether the corporate social responsibility is fulfilled or not affects the interests of the stakeholders. Stakeholders also have some problems in promoting corporate social responsibility.

\subsubsection{Lack of Effective Independent Social Interest Groups}

Stakeholders can restrict the behavior of corporations to a certain extent. At present, the social interest organizations that have certain restriction and influence on the corporation mainly include the Consumer Association, the Environmental Protection Organization and so on. However, China's Consumer Association was established in 1983, and the Environmental Protection Organization was established in 1994, which are still in the primary stage of development and lack the mature organizational model and activist strategy. At the same time, these organizations which often have multiple identities and complex social and economic functions and have strong official color still lack independence, so that they will not effectively protect the interests of consumers and stakeholders. This not only leads to the weakening of the direct force of corporate social responsibility, but also is not conducive to the introduction of relevant laws and regulations.

\subsubsection{The Strength of the Direct Stakeholders Is Weak}

The direct stakeholders of the corporation mainly include the corporate internal employees and corporate products consumers. When the interests of employees and consumers are violated, they have the right to protect their interests. Although the labor contract and the protection of employees' rights and interests are clearly defined in the labor law, yet many private companies still do not sign labor contracts with employees, whose interests can not be protected by law. Employees often endure and adapt to the harsh working environment, harsh conditions, wage arrears etc. under the pressure of social competition and employment. When their interests are infringed, they do not know how to protect their right. When the interests of consumers are damaged, they can protect their legitimate rights according to the provisions of the consumer rights and interests law. But the principle of the burden of proof in our country is "who advocates, who proof" and corporate important information is not completely open, so consumers are difficult to prove, and their rights and interests are not guaranteed. This situation exists in Gansu province and even the whole country. Therefore, the direct stakeholders that have weak strength are in the absolute disadvantage in comparison with the corporation.

\section{Measures to Promote the Social Responsibility of Corporations in Gansu Province under the Background of Low Carbon Economy}

In view of the problems in the promotion of corporate social responsibility in Gansu Province, this paper will look for solutions from the following aspects:

\subsection{Measures Taken by Corporations Themselves}

\subsubsection{Corporations Should Raise Their Sense of Social Responsibility}

The level of corporate social responsibility awareness directly affects the performance of corporate social responsibility, and in order to improve the social responsibility of corporations in Gansu Province, we should proceed from the following aspects:

First, we should introduce the concept of social responsibility in corporate culture. Every corporation has its special cultural connotation, through introducing the concept of corporate social responsibility in the corporate culture not only can continuously improve the awareness of social responsibility of corporation managers, but also can create a good corporate image and encourage corporations to actively undertake corporate social responsibility. 
Second, we should set up the correct moral judgment standard. Correct standards of moral judgments can regulate the management and employee's behavior, form a good moral judgment values in the corporation internal, so that makes the corporation take the social responsibility automatically and willingly.

Third, we should accept the training of corporate social responsibility knowledge. The main reason for the weak awareness of corporate social responsibility is that the understanding of connotation of corporate social responsibility is not clear. Corporate managers and their employees should be trained in the knowledge of corporate social responsibility to learn the relevant knowledge, reverse the concept, consciously save raw materials, reduce pollution emissions, produce qualified products and so on in the production and operation activities.

3.1.2 Corporations Should Accumulate Capital, and Continuously Improve the Ability to Undertake Social Responsibility

Capital accumulation is the pursuit of every corporation, only through the accumulation of capital, can corporations continue to develop on the basis of survival. For different scale corporations, the ability to undertake corporate social responsibility is different. Many small and medium-sized corporations in Gansu Province cannot afford more corporate social responsibility due to the lack of capital accumulation and the limited funds. Therefore, the corporation managers should continue to improve the management level, make development strategy, govern the corporation effectively, enhance the financial strength of corporations and the ability to undertake corporate social responsibility continuously.

\subsection{Measures Taken by the Government}

The government has the important compulsory binding force on the corporate social responsibility. It plays an important role in the process of promoting corporate social responsibility. For the government, mainly to take the following measures:

3.2.1 The Government Should Perfect the Policy, Increase Publicity and Training Efforts on Corporate Social Responsibility

\subsubsection{The Government Should Perfect the Relevant Policies of Corporate Social Responsibility}

The authority of the system is bound to play an important role in the process of corporate social responsibility. Lack of the system will be the bottleneck of corporate social responsibility. It is imperative to establish and perfect a set of perfect law enforcement systems of corporate social responsibility. The government must play its role to change the requirements of the relevant corporate social responsibility into a detailed legal provisions and rules and regulations as soon as possible in order to promote the performance of corporate social responsibility through the authority of the government. Gansu province should comply with the relevant laws and regulations of the state government and develop a number of supporting rules and regulations according to their own characteristics in order to adjust the difference which caused by the region, industry, and size in the process of the performance of corporate social responsibility.

\subsubsection{The Government Should Strengthen the Publicity and Training of Corporate Social Responsibility}

Government is the booster of corporate social responsibility. In order to increase publicity efforts, we should consider from the following aspects: Firstly, the government should take business management or legal representative as the focus of publicity and training, so that the business leader has the awareness of social responsibility. It also can avoid the deviation with the corporation social responsibility target and the low carbon economy development target appearing in the target of the corporation. Secondly, the government should make the corporations which fulfill the corporate social responsibility best as examples study through vigorous publicity, and expose corporations which fulfill the corporate social responsibility worst in order to play an exemplary role. Finally, the government should also prepare corporate social responsibility Knowledge Manual, organize regular training to encourage corporations to learn and communicate.

3.2.2 The Government Should Establish a Standardized Evaluation and Supervision System and Strengthen the Enforcement of Laws and Regulations

\subsubsection{A Standardized Evaluation System of Corporate Social Responsibility Should Be Established}

The imperfect of evaluation standard of corporate social responsibility can lead to the inability to accurately compare for corporations. Therefore, the government needs urgently to establish a set of social responsibility evaluation systems.

First, we should set out the social responsibility evaluation indicators of corporations in different industries. The lack 
of industry evaluation index leads to the benevolent see benevolence, the wise see wisdom, and the evaluation results have lost impartiality. For different industries, the selection of evaluation indicators should also be different.

Second, we should regulate the weight of the evaluation indicators of corporate social responsibility in different industries. The determination of weight has always been a difficulty in the theoretical research, and there is a certain subjectivity in judging the degree of importance of indicators which makes the evaluation result have certain subjectivity. The government should consult with the experts at home and abroad to determine the relative importance of the indicators, so as to determine the weight. In this way, the social responsibility performance of the same industry corporations can be comparable.

Third, we should make out the evaluation criterion of corporate social responsibility in different industry. It is convenient for the corporation to carry on the historical comparison after using a certain method to evaluate the performance of a corporate social responsibility, but it cannot measure the level of the corporate social responsibility performance. Therefore, the evaluation criteria should be formulated in different industries and divided into different levels, so as to measure the level of corporate social responsibility performance.

\subsubsection{A Standardized Corporate Social Responsibility Supervision System Should Be Established}

In order to promote the performance of corporate social responsibility, the government should raise the awareness of supervision and establish a standardized system of social responsibility. The government should proceed from the following aspects:

First, we should improve the awareness of the government's supervision. Government supervision is a powerful booster for corporations to fulfill their social responsibilities. If there is a lack of supervision, the performance of corporate social responsibility will be in a state of confusion. Therefore, the first task of establishing the supervision system is to improve the supervision awareness of government departments. Only when the supervision awareness is enhanced, is it possible to translate awareness into action and fulfill the supervision responsibilities better.

Second, we should define the scope of responsibilities of each supervision department. The supervision department should clarify the rights and obligations of each staff and decompose the supervision responsibilities to specific individuals. Only when the individuals achieve the target of responsibility, can the responsibility target of entire supervision department be achieved.

Third, we should establish the incentive and restraint mechanism of the supervision department. Effective incentive and restraint mechanism can mobilize the enthusiasm of the regulators effectively. However, because Gansu province has not yet formed a set of scientific and effective incentive and restraint mechanism of corporate social responsibility, corporate social responsibility assessment has remained at the level of qualitative assessment and cannot form a constraint which leads to virtual. Therefore, it is necessary to develop plans to promote corporate social responsibility. The government of Gansu province should make clear the goal of promoting social responsibility, determine the focus of the promotion of social responsibility in different period and establish the corresponding incentive and restraint mechanism, so as to promote the implementation of corporate social responsibility gradually.

\subsection{Measures Taken by the Other Stakeholders}

In addition to the corporation itself and the government, the other stakeholders should also take certain measures to promote the performance of corporate social responsibility.

\subsubsection{We Should Establish the Effective Independent Social Interest Organization}

To establish the effective independent social interest organization, we should proceed from the following aspects:

First, the rights and responsibilities of the external social interest organizations should be defined through legal procedures. Only if the range of the rights and responsibilities is clear, can the external social interest organizations exercise its rights sufficiently and represent the interests of the masses. Of course, the definition of rights and responsibilities of the external social interest organizations needs the help of government departments. The government should help them to establish and legalize the range of rights and responsibilities.

Second, we should strengthen the independence of the external social interest organizations, and reduce government intervention. Because the government is the social overall regulator, the external social interest organizations are constrained by the government. The government can guide the external interest organizations to supervise the behavior of corporations through the collection of relevant data, provide useful information, etc, in order to compensate for the omission of the government's administrative management in corporation management. Although the government departments play an important role in the process of the implementation of the rights and 
responsibilities of the external interest organizations, the government departments should reduce administrative intervention as far as possible in the management of external interest organizations, so as to make the external interest organizations play their functions independently.

\subsubsection{We Should Enhance the Strength of the Direct Stakeholders}

3.3.2.1 We Should Enhance the Rights Awareness of Consumers, and Enhance the Ideological Power of Direct Stakeholders

In recent years, although the consumer rights awareness has increased, it has not reached a certain height. When consumers' rights and interests are violated, consumers just complain more, rather than put into action to safeguard their legitimate rights and interests. For example, one thing happened in Lanzhou City, Gansu Province that the benzene exceeded in tap water in 2014, the broad masses of the people have complained, and the events such as abuse and fighting can be seen everywhere, but the people and corporations who stand out to safeguard rights and interests really can be counted on one's fingers. Low awareness of rights cannot promote the performance of corporate social responsibility effectively. It is imperative to enhance the awareness of the rights of consumers in Gansu province comprehensively. The government should strengthen the propaganda of consumer rights which can make consumers fully understand their own rights and interests and know the path to protect their interests through advertising, knowledge training, case study, issuing brochures, etc., so as to strengthen their ideological strength.

\subsubsection{We Should Mobilize the Power of the Public and Enhance the Power of Action of Direct Stakeholders}

The improvement of consumer's rights awareness is an important external supervision power of corporate social responsibility, but safeguard legal rights need a certain cost, when the cost is too high, consumers may give up their rights behavior. Lack of action is one of the reasons for the protection of consumers' rights and interests. Therefore, when the activist events occur, we should mobilize the social public power to enhance group cohesion by taking the cost decentralized strategy to disperse individual costs into groups and reduce the cost of individual rights, in order to achieve greater group action force.

\section{Conclusion}

The performance of corporate social responsibility is conducive to the sustainable development of enterprises and society. Under the background of low carbon economy, the performance of corporate social responsibility should pay more attention to environmental responsibility, and the performance of environmental responsibility has a direct impact on the development of low carbon economy. Therefore, only when the enterprises fulfill their social responsibility actively, can we promote the development of low-carbon economy better. This paper analyzes the problems existing in the process of promoting the social responsibility of enterprises in Gansu province and puts forward the corresponding measures that should be taken from the enterprise itself, the government and other stakeholders etc, in order to promote the performance of corporate social responsibility better. The research results of this paper can not only play a guiding role in the promotion of corporate social responsibility in Gansu province, but also can be used as a reference for other provinces and cities to promote corporate social responsibility. At the same time, it can also enrich the theory of corporate social responsibility. The deficiency of this paper is the lack of data support which can be used to analyze the problems existing in the process of the performance of corporate social responsibility in Gansu Province, which will be the focus of future research to the author.

\section{References}

Ji, T. (2010). Corporate social responsibility in the perspective of low carbon economy -- Interpretation and analysis. Economic Research Guide, 32, 217-219.

Tian, H., \& Jiang, Y. (2014). Research on the dynamic mechanism of corporate social responsibility performance. Audit and Economic Research, 6, 65-74.

Xu, H., \& Zhu, X. (2012). Evaluation indicators of corporate social responsibility from the perspective of low carbon economy. Chinese Soft Science, 1, 153-159.

Zhang, C., \& Deng, X. (2011). Social responsibility of corporations in the era of low carbon economy. Journal of Chongqing University of Science and Technology (Social Science Edition), 3, 86-87.

Zhang, L., Ma, X., \& Li, M. (2013). Research on the evaluation system of corporate social responsibility under the background of low carbon economy. Research on science and technology management, 5, 67-70. 